\title{
Efficacy of curative applications of submicron chitosan dispersions on anthracnose intensity and vegetative growth of dragon fruit plants
}

\begin{abstract}
The antifungal potential of submicron chitosan dispersions (SCD) and its effect on the vegetative growth of dragon fruit plants were studied under field conditions. There was a reduction in disease incidence (15.65\%) with a severity score of 1.60 in plants treated with SCD of $600 \mathrm{~nm}$ droplet size of $1.0 \%$ chitosan compared to the control plants. Moreover, a significant increase was also observed among the treatments in terms of number of shoots per cutting, stem diameter and shoot length. However, the highest number of shoots (19), maximum stem diameter $(0.23 \mathrm{~m})$ and maximum stem length $(2.80 \mathrm{~m})$ were observed in plants treated with SCD of $600 \mathrm{~nm}$ droplet size of $1.0 \%$ chitosan. Similarly, chlorophyll content were also high in plants receiving SCD of $600 \mathrm{~nm}$ droplet size of $1.0 \%$ chitosan. Therefore, it can be concluded from the results that, instead of applying chitosan in the conventional form, it can be more effective as an antifungal agent as well as plant growth enhancer when applied in the form of submicron dispersions.
\end{abstract}

Keyword: Colletotrichum gloeosporioides; Chlorophyll content; Disease severity; Submicron chitosan dispersions 